\title{
Dieta ideal versus desempenho esportivo: um estudo sobre os estereótipos nutricionais aplicados por triatletas
}

\section{Ideal diet versus athletic performance: a study about nutritional stereotypes applied by triathletes}

\author{
Patrícia Kanno 1 \\ Misael Rabelo 1 \\ Gislane Ferreira de Melo ${ }^{1}$ \\ Adriana Giavoni 1
}

1 Universidade Católica de Brasília. Programa de Pós-Graduação Stricto Sensu em Educação Física. Brasília, DF. Brasil

Recebido em 28/03/09 Revisado em 16/06/09 Aprovado em 04/08/09
Resumo - O termo estereótipo designa algumas percepções generalizadas que determinados grupos atribuem a um indivíduo, a grupos, objetos e/ou eventos. Objetivo: O objetivo do estudo foi avaliar as prioridades que nutricionistas e triatletas atribuem aos alimentos, visando à aquisição de um melhor desempenho esportivo. Método: A amostra foi composta por 56 sujeitos, divididos em dois grupos: Nutricionistas (G1, n = 29) e Triatletas (G2, n = 27). O Questionário de Prioridade Alimentar (QPA), composto por grupos alimentares, foi utilizado para avaliar a importância atribuída a cada alimento para o desempenho atlético. Resultados: Para a análise dos dados, cada alimento foi agrupado em uma das oito categorias da pirâmide alimentar. Foram elaboradas médias aritméticas para as categoriais e realizados testes t para amostras independentes para comparar as prioridades de nutricionistas e triatletas em relação às mesmas. Não foram encontradas diferenças significativas em relação às categorias Hortaliças, Leguminosas, Frutas e Açucares/Doces e, também, para o item café preto. Entretanto, Cereais/Pães/Tubérculos e Carnes/Ovos foram superestimados pelos triatletas enquanto os Leites/Produtos Lácteos e Óleos/Gorduras foram subvalorizados. Conclusão: Os triatletas supervalorizam alguns macronutrientes (carboidratos e proteínas) em detrimento de outros, como os lipídeos.

Palavras-chave: Comportamento alimentar; Desempenho atlético; Estereótipos.

Abstract - Stereotype is a term designated to some generalized perceptions that people attribute to another individual, groups, objects and/or events. Objective: The purpose of this study was to evaluate the priorities that nutritionist and triathletes attributed to food to enhance the sport performance. Method: The sample was composed by 56 subjects, splited in two groups: Nutritionists (G1, $n=29)$ and Triathletes (G2, n= 27). The Intake Food Priority Questionnaire (QPA), composed by food groups, was used to evaluate the importance of each food in the athletic performance. Results: To the data analysis, each food was grouped into one of the eight categories designed in nutrition pyramid. An arithmetic means were elaborated to categories and it was performed t tests for independent samples to compare nutritionists and triathletes priorities about each category. There were no differences between groups in Vegetables, Leguminous, Fruits and Sugar/Candies categories and, also, to the black coffee item. However, the triathletes overestimated the Cereals/Breads/Tubercle and Meat/Eggs categories and underestimated the Milk/Dairy Products and Oils/Fat categories. Conclusion: The triathletes overestimated some macronutrients (carbohydrates and proteins) in detriment from another, like lipids.

Key words: Diet behavior; Athletic performance; Stereotypes. 


\section{INTRODUÇÃO}

A mente humana possui diversas dimensões, as quais processam informações relacionadas a si e ao meio em que vive. Estas dimensões são formadas por esquemas cognitivos cuja principal função está em perceber, categorizar, organizar e comparar estímulos 1 . Os esquemas comportam estruturas de cognições bem organizadas em relação à sociedade, a uma pessoa, ao meio, ao grupo ou até em relação a uma situação específica, resumem as experiências passadas do indivíduo e organizam a ampla variedade de informações relativas a si e aos outros ${ }^{2}$. Sua função está em reduzir a entrada maciça de informações: a) processando informações consistentes com a sua estrutura mais rapidamente; b) regendo as inferências e julgamentos a respeito de pessoas e/ou objetos; e c) reduzindo a ambiguidade de uma situação, favorecendo um modo particular de percepção e interpretação do evento ${ }^{3}$. Subdividem-se em uma série de categorias, dentre as quais estão os esquemas de grupo, também denominados de Estereótipos.

Estereótipos são considerados como supergeneralizações que membros de um determinado grupo emitem de uma entidade qualquer, seja um grupo social, familiar, uma categoria social, dentre outros $^{1,4}$. Este termo é formado por duas palavras gregas, stereos, que significa rígido, e tupos/typos, que significa traço, marca, tipo, termo extraído das artes gráficas e, mais especificamente, da tipografia, que designa as pranchas, clichês ou moldes mecânicos que são utilizados em impressões, repetidamente. No plano histórico, a psiquiatria do século XIX utilizava a palavra estereotipia para se referir à repetição mecânica e frequente de um mesmo gesto, postura ou fala em pacientes que sofriam de dementia pra$e c o x^{5,6}$. Em Ciências Sociais, o termo foi utilizado, pela primeira vez, por Lippmam, em 19225,7.

Este termo ${ }^{5,8}$ tem sido utilizado para fazer referência às imagens por demais generalizadas que os indivíduos possuem de um grupo e/ou evento, as quais desencadeiam uma série de comportamentos com o mínimo de informação $0^{9-11}$. Embora reconhecidos como construções exageradas e, em geral, distorcidas da realidade, os indivíduos não possuem consciência do impacto que estas exercem sobre os seus julgamentos. Assim, aplicado ao contexto esportivo, pode-se inferir que os estereótipos venham a desencadear uma série de comportamentos disfuncionais nos atletas, principalmente, no que diz respeito aos seus comportamentos alimentares. Devido ao fato dos atletas não apresentarem um amplo conhecimento do campo nutricional, estes tenderão a criar imagens a respeito dos alimentos benéficos e maléficos para os seus desempenhos, imagens estas elaboradas a partir de suas vivências no âmbito esportivo. Estas construções cognitivas geram padrões de respostas, as quais os induzem a dar prioridade para determinados grupos alimentares em detrimento de outros.

Muito embora esteja ocorrendo um forte crescimento na área da nutrição desportiva, observa-se que existe um elevado grau de desinformação entre atletas e treinadores, os quais, rotineiramente, assumem a prescrição dietética do atleta. $\mathrm{O}$ objetivo da nutrição, entretanto, está em oferecer conhecimento básico e específico que permita, dentre outros aspectos, a prescrição de uma dieta adequada e individualizada. Profissionais desta área possuem embasamento teórico e prático que permite melhorar o desempenho fisiológico, a partir de técnicas dietéticas e intervenções nutricionais individualizadas e balanceadas com aporte necessário de substratos ${ }^{12}$.

Em relação ao universo atlético, entretanto, nota-se que os atletas possuem padrões alimentares específicos. Muitos acreditam que o baixo consumo de carboidratos e o alto consumo de proteínas são fundamentais para o rendimento atlético. Segundo Rossi et al. ${ }^{13}$ "Este comportamento pode ser devido a crenças nutricionais incorretas e a supervalorização dos alimentos protéicos em detrimento dos carboidratos, referenciados como responsáveis pelo ganho de peso e maior deposição de gordura".

Estudos vêm demonstrando que devido às suas crenças, os atletas apresentam alto consumo de proteínas e lipídeos e baixo consumo de carboidratos ${ }^{14-15}$ , confirmando que as crenças nutricionais podem influenciar negativamente o desempenho físico. De acordo com Bassit e Mahverdi (1998), "Hoje, sabe-se que a ingestão de carboidratos durante provas longas mantém o rendimento elevado, e que a utilização desta estratégia durante os treinos permite ao atleta trabalhar com maior carga por mais tempo"14.

De igual forma, a cafeína ${ }^{16}$ vem sendo utilizada "no intuito de protelar a fadiga e aumentar o poder contrátil do músculo esquelético e/ou cardíaco, com consequente, melhora em exercício de longa duração"16-17, sendo que os resultados dos estudos têm se mostrado contraditórios, apresentando relações positivas e negativas da cafeína com o desempenho desportivo.

Estes dados revelam que existe um descompasso entre a construção cognitiva dos atletas em relação aos alimentos e os reais benefícios de uma ingestão nutricional equilibrada. Estas crenças nutricionais 
são resultantes das informações veiculadas pelo meio social, desportivo e as próprias vivências dos atletas neste meio. Estas informações acabam sendo assimiladas, categorizadas e organizadas em esquemas cognitivos relativos à nutrição, os quais agem como filtros perceptivos, influenciando as cognições, preferências e os comportamentos alimentares dos atletas.

Assim, o objetivo deste estudo foi verificar quais são os estereótipos nutricionais de triatletas em relação à dieta ideal, de tal forma que esta propicielhes o ápice de seus desempenhos atléticos.

\section{PROCEDIMENTOS METODOLÓGICOS}

\section{Amostra}

A amostra total foi composta por 56 sujeitos, subdivididos em dois grupos: a) grupo $1(\mathrm{n}=29)$ - formado por nutricionistas (não envolvidos com os atletas que compõem o grupo 2) e b) grupo 2 (n =27)-composto por triatletas do sexo masculino. Este projeto encontra-se aprovado pelo Comitê de Ética de uma Instituição, sob o n ${ }^{\circ} 77 / 2007$.

\section{Instrumentos}

Ambos os grupos responderam o Questionário de Prioridade Alimentar (QPA). Este questionário foi elaborado para avaliar a importância atribuída pelo respondente a cada alimento e, posteriormente, agrupá-los nas categorias previstas pela pirâmide alimentar ${ }^{18-19}$. É composto por uma lista de alimentos, os quais se encontram inseridos em conjuntos cujas denominações seguem o senso comum, tais como: Pães e Biscoitos, Bebidas, Frutas, Frutas Secas, Massas, dentre outras. Cada alimento é avaliado através de uma escala que varia de 1 (indicando que o alimento não é importante) à 5 (indicando que o alimento é muito importante). Por se tratar de um questionário para agrupar os alimentos nas categorias da pirâmide e não se caracterizar como um teste ou escala psicométrica que visa avaliar um constructo subjacente e/ou um determinado desempenho individual, este questionário não necessita de validação prévia.

O QPA foi elaborado em duas versões que diferiam apenas em suas instruções. Uma primeira versão, aplicada nos triatletas, solicitava que estes descrevessem a importância de cada alimento para a aquisição de um melhor desempenho atlético e a versão aplicada aos nutricionistas, a qual solicitava que os mesmos utilizassem a lista de alimentos para descrever a importância de cada alimento para que os triatletas viessem a atingir os seus melhores desempenhos esportivos.

\section{Procedimentos metodológicos}

Os questionários foram aplicados individualmente pelos próprios pesquisadores, tanto para o grupo de triatletas quanto para o grupo de nutricionistas. Os triatletas responderam o QPA antes de seus treinos de musculação nas academias, enquanto os nutricionistas responderam durante suas atividades no projeto institucional, denominado de Alimentação Saudável.

\section{Análise Estatística}

Utilizando-se o programa Statistical Package of Social Sciences (SPSS-15.0), foram realizadas análises descritivas (média e desvio-padrão) e inferenciais do tipo teste $t$ para amostras independentes, para comparar as percepções dos triatletas e nutricionistas com relação à dieta para se atingir o melhor desempenho atlético. Estipulou-se erro de 5\% em todas as análises inferenciais realizadas.

\section{RESULTADOS}

Os alimentos que compõem o QPA foram agrupados nas categorias da pirâmide alimentar, denominadas de: Cereais/Pães/Tubérculos, Hortaliças, Frutas, Leites/Produtos Lácteos, Carnes/Ovos, Leguminosas, Óleos/Gorduras e Açucares/Doces. Para cada categoria foi obtida a média aritmética dos alimentos que a compõe.

O grupo 1, composto por 29 nutricionistas, caracterizou-se por estar constituído por 93,1\% de mulheres, com idade média de 29,28 ( \pm 8,28) anos, todas com o terceiro grau completo e o grupo 2 foi formado por 27 triatletas do sexo masculino, com idade média de 22,15 ( $\pm 2,52)$ anos e nível de escolaridade igual ou superior ao segundo grau completo $(55,6 \%)$

A tabela 1 apresenta as médias e desvios-padrões, bem como, os níveis de significância obtidos para as categorias da pirâmide.

Tabela 1. Médias, desvios-padrões e níveis de significância obtidos para as categorias da pirâmide alimentar.

\begin{tabular}{lccc}
\hline Categorias & Nutricionistas & Triatletas & $p$ \\
\hline Cereais & $3,00( \pm 0,35)$ & $3,16( \pm 0,19)$ & $0,04^{*}$ \\
Hortaliças & $3,62( \pm 0,55)$ & $3,73( \pm 0,53)$ & 0,44 \\
Frutas & $3,26( \pm 0,45)$ & $3,44( \pm 0,22)$ & 0,06 \\
Leites e produtos & $2,76( \pm 0,45)$ & $2,30( \pm 0,39)$ & $0,001^{*}$ \\
lácteos & & & \\
Carnes e Ovos & $2,45( \pm 0,40)$ & $2,70( \pm 0,37)$ & $0,02^{*}$ \\
Leguminosas & $3,24( \pm 0,58)$ & $3,19( \pm 0,44)$ & 0,69 \\
Óleos e gorduras & $2,70( \pm 0,63)$ & $2,22( \pm 0,37)$ & $0,001^{*}$ \\
Açucares e Doces & $1,95( \pm 0,39)$ & $1,95( \pm 0,29)$ & 0,96 \\
\hline
\end{tabular}

$* p<0,05$ 
Não foram encontradas diferenças significativas entre os grupos para as categorias Hortaliça, Frutas, Leguminosas e Açucares/Doces e, também, para o item café preto. Entretanto, os triatletas superestimaram os alimentos das categorias Cereais/ Pães/Tubérculos e Carnes/Ovos e subestimaram as categorias Leites/Produtos Lácteos e Óleos/Gorduras quando comparados aos nutricionistas.

\section{DISCUSSÃO}

Observa-se, a partir dos resultados, que os estereótipos nutricionais dos triatletas não apresentam discrepâncias com estudos realizados de forma direta a partir de recordatórios alimentares, os quais descrevem a priorização de dietas hiperprotéicas por parte dos atletas ${ }^{13,15}$. Nota-se, inclusive, que o conteúdo dos seus estereótipos são condizentes com os resultados científicos, os quais apresentam a relação entre dietas hiperprotéicas e redução do percentual de gordura ${ }^{13}$ e consumo de carboidratos com a manutenção do rendimento esportivo ${ }^{14}$.

No entanto, por se tratar de um estereótipo, ou seja, de um padrão perceptivo resultante de um esquema cognitivo composto por informações parciais, sabe-se que as lacunas decorrentes do desconhecimento sobre o tema serão preenchidas por informações compatíveis com o esquema já estruturado, gerando, muitas vezes, percepções distorcidas $^{9-11}$. Assim, embora os esquemas dos atletas apresentem informações condizentes com os resultados obtidos cientificamente, as lacunas tendem a gerar comportamentos alimentares inadequados, nos quais os atletas supervalorizam determinadas categorias de alimentos em detrimento de outras.

Os resultados revelam que os atletas valorizam o alto consumo protéico, mas desconsideram o aporte de vitaminas e minerais, disposição genética, equilíbrio no balanço energético, dentre outros ${ }^{20-22}$. Também desconhecem as consequências de uma dieta hiperproteica a qual ocasiona aumento do risco de doença cardíaca, predisposição para acidose metabólica, levando o atleta à fadiga mais rapidamente; osteoporose em função da diminuição da absorção de cálcio além de disfunções renais, pois diminui os níveis de excreção de citrato na urina, acarretando a formação de cálculos renais s3-24 $^{23}$.

Em relação ao consumo de carboidratos, acreditam que o alto consumo de massas desencadeará um melhor desempenho durante a competição, levando a vitórias, mas esquecem-se de que o excesso destes alimentos pode causar hipertrigliceridemia, propensão a Diabetes Mellitus tipo II e doenças coronarianas ${ }^{25}$.
Estas "crenças cognitivas" ou estereótipos nutricionais podem estar, inclusive, conduzindo os atletas para a utilização de esteróides anabolizantes ${ }^{20-21}$.

Os resultados ainda demonstraram que os atletas desvalorizam os lipídios. Muito possivelmente, as informações estruturadas em seus esquemas cognitivos a respeito dos lipídios sejam aquelas de cunho popular, geradas na mídia, onde os lipídios retratados são aqueles de má qualidade, ricos em gorduras saturadas e gorduras trans, os quais se encontram vinculados ao aumento de gordura corporal, hipercolesterolemia, doenças coronarianas, dentre outros. Entretanto, desconhecem a importância das gorduras insaturadas/poliinsaturadas, que correspondem as gorduras de boa qualidade. Estes tipos de gorduras, além de serem benéficas para a saúde, previnem doenças crônicas não transmissíveis e aumentam o rendimento esportivo, pois restringem a utilização do glicogênio muscular, evitando a fadiga ${ }^{26}$.

\section{CONCLUSÃO}

Conclui-se, portanto, que a constituição dos esquemas cognitivos dos triatletas em relação aos conceitos nutricionais, influenciam as suas condutas posteriores quanto as prioridades atribuídas a determinados alimentos em detrimento de outros. Isto se confirma, pois as prioridades alimentares destes atletas foram constatadas com uma prescrição dietética conduzida por profissionais da área de nutrição.

Assim, pode-se conjecturar que as médias mais elevadas obtidas para as categorias Cereais/Pães/ Tubérculos e Carnes/Ovos descrevam a supervalorização que os triatletas atribuem aos carboidratos e proteínas, quando comparados às médias obtidas para os nutricionistas, os quais idealizaram uma dieta equilibrada.

De igual forma, os triatletas subestimaram os lipídeos, demonstrando que muitas das informações contidas em seus esquemas cognitivos relativos à nutrição são inconsistentes e, muito provavelmente, provenientes de informações generalizadas da mídia e do próprio ambiente esportivo.

Estes resultados confirmam a própria natureza da estrutura e funcionamento dos esquemas, pois uma vez que os mesmos são formados ao longo da vida, a partir das informações, conceitos, imagens, crenças, valores e experiências individuais, estes contém aspectos condizentes com a ciência da nutrição, assim como lacunas as quais serão preenchidas por informações generalistas, mas condizentes 
com o restante da estrutura do esquema.

Seu propósito está em dar sentido ao estímulo percebido, de forma que os mesmos possam ser assimilados e interpretados de acordo com a estrutura do esquema já constituída. Assim, observa-se que os triatletas apresentaram uma estrutura cognitiva relativa à nutrição na qual existem informações positivas, relacionando os carboidratos e proteínas ao rendimento esportivo e informações negativas em relação aos lipídeos, as quais podem contribuir para um desequilibro da sua conduta dietética.

Como não foram encontrados estudos em literatura relacionando os esquemas cognitivos com a área de nutrição, este estudo caracterizase como original, mas abre a possibilidade para que novos estudos sejam realizados, procurando esclarecer tal relação. Um estudo significativo e complementar a este seria a comparação entre as dietas que os atletas prescrevem para si, buscando um melhor rendimento e as suas compreensões a respeito dos benefícios da utilização adequada dos macronutrientes e malefícios da ausência ou excessos destes.

\section{REFERÊNCIAS BIBLIOGRÁFICAS}

1. Michener HA, DeLamater JD, Myers DJ. Psicologia Social. 3 ed. São Paulo: Pioneira, 2005.

2. Markus H, Crane M, Bernstein S, Siladi M. Self schemas and gender. J Pers Soc Psychol 1982;42:38-50.

3. Shaller M, Latank B. Dynamic Social Impact and the Evolution of Social Representations: A Natural History of Stereotypes. J Commun 1996;46(4):64-77.

4. Markus H. Self schemata and processing information about the self. J Pers Soc Psychol 1977;35(2):63-78.

5. Pereira ME. Psicologia social dos estereótipos. Pers Soc Psychol Rev 2001;1(2):106-128.

6. Yzerbyt V, Schadron G. Estereotipos y juicio social. In: Bourhis RY, Morales JF, Moya M.(editores) Tratado de Psicologia Social. Madrid: Ed. Síntesis; 1996. p. 113-138.

7. Brubaker TH, Powers EA. The Stereotype of "Old". A Review and Alternative Approach. J Gerontol 1976;31(4):441-447.

8. Martinez MMC. Análise Psicossocial del Prejuicio. Madrid: Editorial, 1996.

9. Rodrigues A, Assmar E, Jablonski B. Psicologia social. 2 ed. Petrópolis: Vozes, 1999.

10. Giavoni A. Estereótipos sexuais aplicados em nadadoras. Rev Bras Ciên Mov 2002;10(2):27-32.

11. Hepburn R. Memory for the frequency of sexy-typed versus neutral behaviors: implications for the maintenance of sex stereotypes. Sex roles 1985;7(8):771-776.

12. Melby CL, Hill JO. Exercício, balanço dos macronutrientes e regulação do peso corporal. Sports Sci Exc 1999;23(12):1-8.
13. Rossi L, Terapegui J, Castro IA. Restrição moderada de energia e dieta hiperproteica promovem redução ponderal em atletas de elite de karatê. Rev Bras Ciên Mov 2004;12(2):69-73.

14. Bassit RA, Mahverdi MA. Avaliação nutricional de triatletas. Rev Paul Educ Fis 1998;12(1):42-52.

15. Gonçalves MMS, Chelotti CM, Rodrigues T. Avaliação da dieta nutricional de atletas de força: estudo de caso sobre equipe de powerlifting. Rev Bras Nutr Esportiva 2007;1(2):12-22.

16. Altimari LR, Moraes AC, Tirapegui J, Moreau RLM. Cafeína e performance em exercícios anaeróbios. Rev Bras Cienc Farm 2006;42(1):17-27.

17. Triana RO, Machado MV, Atimari LR, Fontes EB, Smirmaul BOC, Gonçalves EM, et al. Efeitos da ingestão de cafeína sobre o limiar de esforço percebido. Motriz 2008;14(3):300-309.

18. Cuppari L. Nutrição clínica no adulto. São Paulo: Manole; 2002.

19. Philippi ST, Cruz ATR, Colucci ACA. Pirâmide alimentar para crianças de 2 a 3 anos. Rev Nutr 2003;16(1):5-19.

20. Juzwiak CR, Paschoal CP, Lopez FA. Nutrição e atividade física. J. Pediatr 2000; 76(3): 349-358.

21. Sossin K, Gizis F, Marquart F, Sobal J. Nutrition beliefs attitudes, and resource use of high school worestling coaches.International. J Sport Nutr 1997;7(3):219-28

22. Short SH, Short WR. Four year study university athletes dietary intake. J Am Diet Assoc 1983;82(6):63245.

23. Anderson JW, Konz EC, Jenkins A. Health advantages and disadvantages of weightreducing diets: a computer analysis and critical review. J Am Col Nutr 2000;19:578-590.

24. Ramos AMF, Gabbai AA, Cintra IP. Impacto nutricional da dieta cetogênica em crianças com epilepsia de difícil controle. Pediatria São Paulo 2004; 26:4:230-9

25. Mahan LK, Escott-Stump S. Alimentos, nutrição e dietoterapia. Editora Roca. 2005.

26. Bernardes D, Manzoni MSJ, Souza CP, Tenório N, Dâmaso AR. Efeitos da dieta hiperlipídica e do treinamento de natação sobre o metabolismo de recuperação ao exercício em ratos. Rev Bras Educ Fís Esporte 2004;18(2):191-200.

\section{Endereço para correspondência}

Adriana Giavoni

Universidade Católica de Brasília, Campus I, QS 07, lote 01, EPCT.

71966-700 - Águas Claras, Brasília, DF. Brasil

E-mail: adriana@pos.ucb.br 